\title{
Vertical Hydraulic Conductivity of Borehole Heat Exchanger Systems Before and After Freeze-Thaw Cycle Stress
}

\author{
Alexander Kirschbaum \\ Jens M. Kuckelkorn \\ Kilian Hagel
}

\begin{abstract}
Quality assurance is a very important aspect in the planning, implementation and operation of borehole beat exchangers (BHE). Within the research project Quality Assurance for Borehole Heat Exchangers (QEWS) the bydraulic sealing behaviour of industrial grouting materials was investigated. Important aspects therein were the capability for sealing between different aquifers and aging resistance against freeze-thaw cycle stress. For this purpose, a large-scale test rig for determining the hydraulic conductivity of borehole heat exchanger systems (BHES) was developed and put into operation. Compared to samples of the pure grouting material, the system samples exbibited significantly increased permeability, which was further increased by freeze-thaw cycle stress. It could be shown that the first freeze-thaw cycle caused the most significant aging effect. Aging caused by further freeze-thaw cycles could be partly compensated by regeneration effects. But the large-scale test rig has a substantial disadvantage: due to the length of the system sample, depending on the bydraulic permeability of the grouting material, the experimental program is very complex and time-consuming. Therefore, a downscaled test rig will be developed within the current project Quality Assurance for Borehole Heat Exchangers II (QEWS II).
\end{abstract}

\section{INTRODUCTION}

In the field of shallow geothermal energy, borehole heat exchangers (BHE) are widely used as low temperature sources for heating and cooling purposes. In Germany, double-U-pipes are frequently used in these systems.

Quality assurance is very important in planning, construction and operation of these systems. Reliable sealing of the borehole over a long period of time has a high priority. The best possible groundwater protection must be ensured and should not be impaired by influences such as improper pressure testing or freeze-thaw cycle stresses. (VDI 4640, 2015)

A long-term stable vertical sealing of the borehole heat exchanger system (BHES) is of fundamental importance for approval by the water authorities, particularly when intersecting different groundwater layers, which are separated by sealing layers. This is not only a matter of the impermeability of the grouting material but also of the overall BHES under in-situ conditions. Therefore, a collective consideration of grouting material, heat exchanger pipes (HEP) and possible installations such as spacers or centering devices as well as the connection to the surrounding soil must be carried out at realistic operating conditions.

Dr. Jens M. Kuckelkorn is head of the Systems Engineering group at the Bavarian Center for Applied Energy Research. Alexander Kirschbaum (alexander.kirschbaum@zae-bayern.de) and Kilian Hagel are research engineers in this group. 
A large-scale test rig was built at the Bavarian Center for Applied Energy Research in Garching near Munich, Germany, to investigate an BHES under realistic pressure and temperature conditions with regard to its hydraulic conductivity. A system sample, $150 \mathrm{~mm}$ in diameter and $3.5 \mathrm{~m}$ long, consisting of grouting material, 4 HEPs with an outer diameter of $32 \mathrm{~mm}$, U-bend, grouting hose and spacers can be installed into this test rig. (Kuckelkorn, et al. 2010; Kuckelkorn and Reuß 2010; Kuckelkorn and Reuß 2012; Reuß, et al. 2012; Kuckelkorn 2013; Anbergen, et al. 2014b; Anbergen, et al. 2015)

Yet, the vertical hydraulic conductivity of a BHES under in-situ conditions and the resistance of the grouting material against freeze-thaw cycle stresses and high temperature gradients has not been satisfactorily investigated.

In the meantime, another test method has been developed, suited to investigate a $7 \mathrm{~cm}$ tall sample with a diameter of around $10 \mathrm{~cm}$ and a central HEP with a diameter of $40 \mathrm{~mm}$ (Anbergen et al., 2012; Anbergen and Sass, 2013; Anbergen et al., 2014a, Anbergen et al., 2014b; Anbergen et al., 2015). This test method also allows for stressing of the sample with freeze-thaw cycles. These samples are comparably short and have only one HEP installed.

In comparison, the large-scale test rig has a substantial disadvantage: due to the length of the system sample and depending on the hydraulic permeability of the grouting material, it can take several weeks to reach a fully saturated condition. From sample preparation to sample disassembly, 4 to 6 months can pass. This is clearly too long to serve as a material testing method for manufacturers.

Therefore, the Bavarian Center for Applied Energy Research is developing a downscaled test rig in a running project. The installation of system samples of lengths up to $100 \mathrm{~cm}$ with a double-U-pipe and diameter of $15 \mathrm{~cm}$ as well as samples with only one HEP and $10 \mathrm{~cm}$ in diameter should be possible (Kirschbaum, et al. 2017).

\section{LARGE-SCALE TEST RIG}

\section{Experimental setup and operation}

The system tests include the evaluation of full BHES-samples in a large-scale laboratory test rig. The system sample has a diameter of $150 \mathrm{~mm}$ and a hydraulic measurement length of $2.75 \mathrm{~m}$. It consists of grouting material, 4 HEPs with a diameter of $32 \mathrm{~mm}$, a U-bend, grouting hose and spacers. The borehole wall is simulated by a plastic tube, which has been sanded on the inside. For this purpose, a suitable sanding process was developed which is intended to prevent water from flowing between the plastic tube and grouting material.

The system sample is prepared by tremie method by filling it with grouting material from bottom to top with the help of a grouting hose, a colloidal mixer and a screw pump. After curing under water for at least 28 days, the system sample is installed into the test rig. The test rig is shown in Figure 1.

According to DIN 18130-1 (DIN 18130-1, 1998) the system sample is saturated with tap water at a pressure of 9 bar after installing it into the test rig. When the saturating process is confirmed the system sample is subjected to a hydraulic gradient at isothermal conditions with the higher pressure at the bottom of the test rig. The volume of the water flowing through the $2.75 \mathrm{~m}$ long measurement section from the bottom to the top of the test rig is recorded.

The permeability coefficient $\left(\mathrm{k}_{\mathrm{f}}\right.$-value) for water, used to characterize porous rocks according to Darcy (Hölting and Coldewey 2008) can be used as a measure for the hydraulic permeability of the entire BHES. Using the recorded volume flow, the mean temperature, the hydraulic gradient and the dimensions of the system sample, the $\mathrm{k}_{\mathrm{f} 10}$-value (water permeability coefficient at $10^{\circ} \mathrm{C}$ ) can be determined.

To determine the influence of freeze-thaw cycle stress or high temperature gradients, the system samples are subjected to predefined thermal stress and, subsequently, measured again. Analogous to the in-situ operation of a BHE the system sample can be frozen from the inside out via the HEPs. The plastic tube simulating a borehole wall and the cell pressure mechanically stabilizes the grouting material of the system sample during the freeze-thaw cycle. A temperature control device allows for defined stressing of the system sample with inlet flow temperatures ranging from $-10{ }^{\circ} \mathrm{C}$ to $+80^{\circ} \mathrm{C}$. It also allows for keeping a constant internal temperature in the thermally insulated pressure vessel during the saturation process and measurements. These isothermal conditions are monitored by several Pt100 
sensors installed in the vessel and system sample. To ensure precise volume measurement, the volumetric meter is installed in a temperature controlled and insulated chamber.
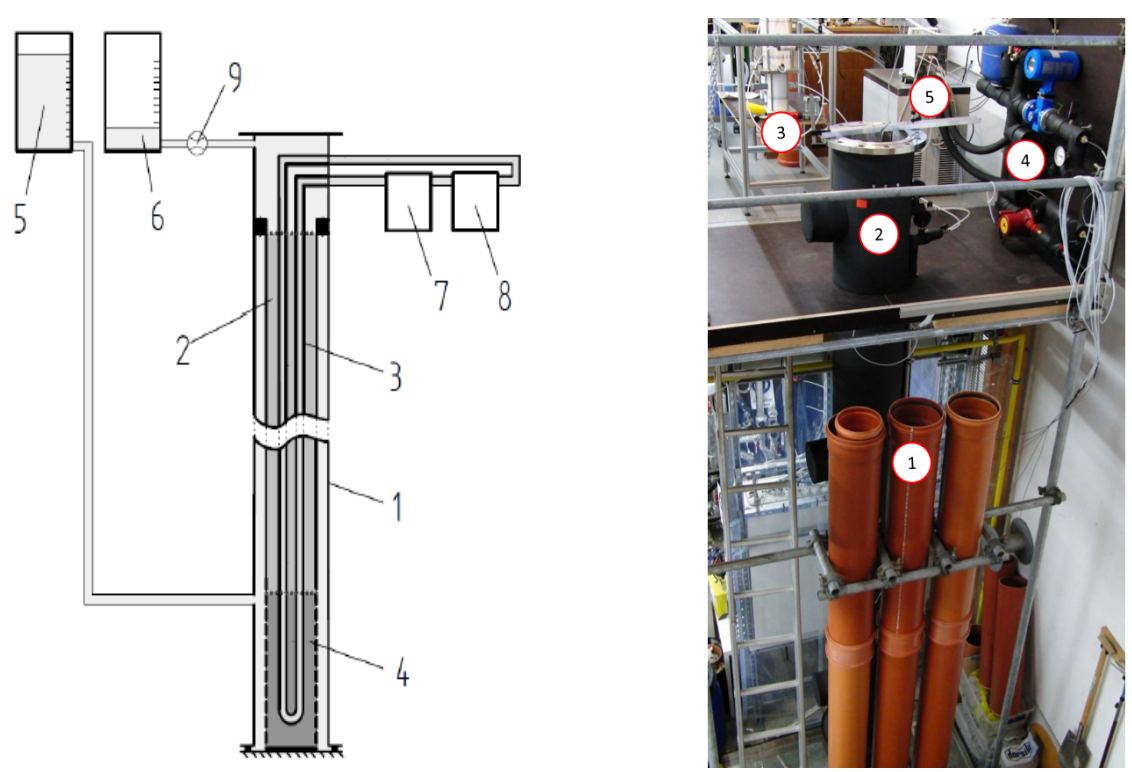

Figure 1 Large-scale test rig for the measurement of the hydraulic conductivity of BHES samples. Left: Schematic construction. The system sample, consisting of grouting material (2), double-U-pipe (3) and a sample bottom with U-bend (4), is installed into the pressure vessel (1). With the help of a cooling and heating device (7 \& 8), isothermal conditions for the measurement and simulation of freeze-thaw cycle stress is possible. Using the pressurized water intake (5), the water outlet (6) and a volume flow sensor (9), the water volume flowing through the system sample from bottom to top is recorded and the hydraulic conductivity of the sample can thus be determined. Right: Picture of the test rig with sample storage for preparing and curing system samples (1), pressure vessel without installed lid (2), volume flow sensor (3), hydraulic circuit (4) and temperature control device (5).

For the design of the large-scale test rig and the experimental procedure, the following parameters were relevant, especially due to their influence on the sealing effect of the grouting materials:

- Mineral composition of the grouting material

- Methodology of mixing and/or properties of the suspension during filling

- Method of injection into the borehole

- Time and duration of the hydraulic pressure test of the in-situ BHE

- Sample age and curing time at beginning of measurement

- Thermal stress, especially minimum temperature and number of freeze-thaw cycles

- Height of the temperature gradient between the HEPs and surrounding rock

Special focus was put on the aging behavior of the grouting materials during freeze-thaw cycle stress and on transferability of the results. Thus, based on the methodology of hydraulic tests of triaxial cells (DIN 18130-1, 1998), the permeability coefficient of several system samples was determined. These system samples had to be comparable to an in-situ borehole heat exchanger regarding their dimensions, properties and the operating conditions. The results were compared to the parameters of standard triaxial cells determined in preliminary material tests. 
So far, four different grouting materials were measured in combination with PE100 HEPs (polyethylene pipes, $32 \mathrm{~mm}$ in diameter), stressed with freeze-thaw cycles, remeasured and visually inspected after removal from the test rig. After preparation, the system samples were stored under water for a curing period of at least four weeks. After installation in the experimental apparatus, the samples were saturated for about four weeks due to their size and the low permeability of the material. The freeze-thaw cycle was defined according to a standard load profile which was derived from data of building facilities measured in operation. Load states of under dimensioned BHES in winter were considered in particular. On this basis, a standard load profile for freeze-thaw cycles was developed in which the inlet fluid temperature of the sample circuit is reduced to $-6^{\circ} \mathrm{C}$ (see Figure 2). For the first 11 freeze-thaw cycles this specified temperature profile was performed on all four system samples.

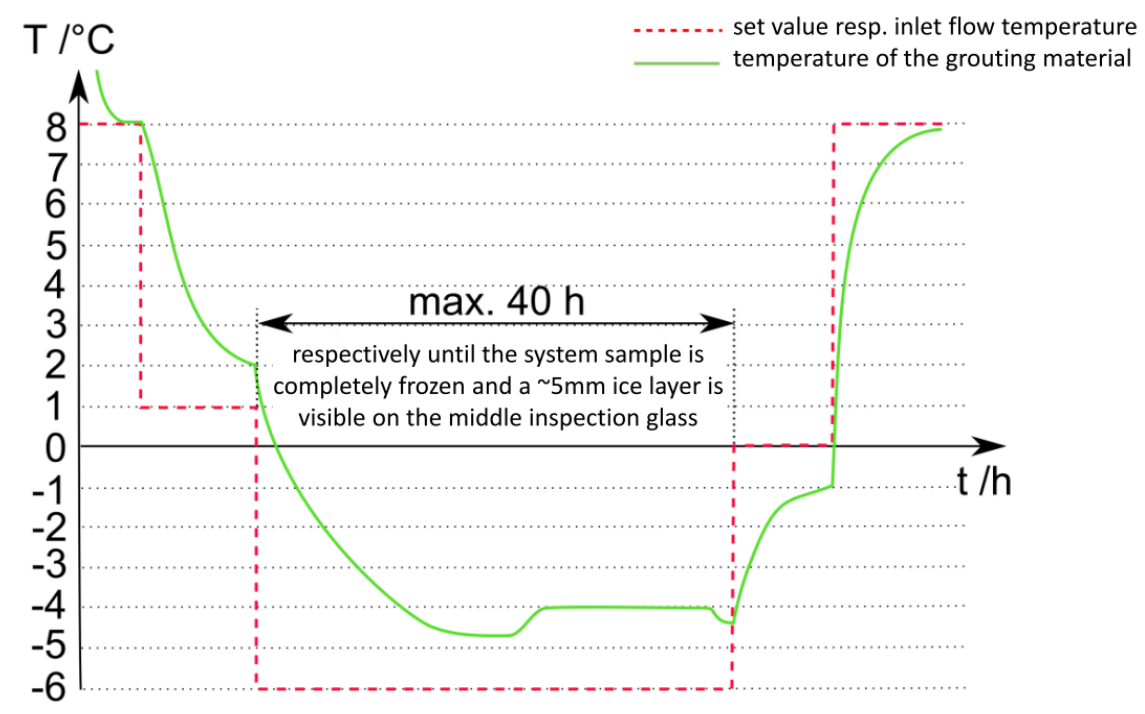

Figure 2 Scheme of the standardized freeze-thaw cycle. After lowering the sample inlet flow temperature to $-6{ }^{\circ} \mathrm{C}$, the reduction in temperature progresses radially from the heat exchanger pipes. The phase change to solid in the grouting material tracks the temperature profile.

\section{Test results for vertical hydraulic conductivity}

The main focus of the system sample tests was on vertical hydraulic conductivity, also in comparison with samples consisting of only the grouting materials; the effect of freeze-thaw cycle stress; visible changes in the structural conditions (e.g. crack formation, ring gap formation); water drifts — for example along the surface of the HEPs.

Furthermore, it had to be ensured that the measuring method was not affected by boundary conditions such as temperature fluctuations or additional water drifts along the "borehole wall". Therefore, the boundary conditions of the individual measurements were varied as follows to check if the $\mathrm{k}_{\mathrm{f} 10}$-values were stable:

- Variation of the hydraulic gradient to check for water flow between sanded plastic tube and grouting material.

- Variation by increasing and reducing the hydraulic gradient to determine storage effects.

- Variation of the experimental temperature to determine the temperature dependence of the method.

The evaluation of the variation showed that the results of the measurements were not affected by the experimental setup. 
The determined values of the system permeabilities of unstressed system samples showed considerable differences between the four system samples, which correlates with the material samples examined in the preliminary tests. It was possible to quantify how the inclusion in a BHE system as well as freeze-thaw cycle stress affects the $\mathrm{k}_{\mathrm{f} 10^{-}}$ value and contribute to an increase in the systems' vertical hydraulic conductivity. In the case of the freeze-thaw cycles, the first thermal stress causes the greatest influence. Figure 3 shows this increase in permeability by comparing the unstressed sample permeability with the results after freeze-thaw cycle for one of the four system samples.

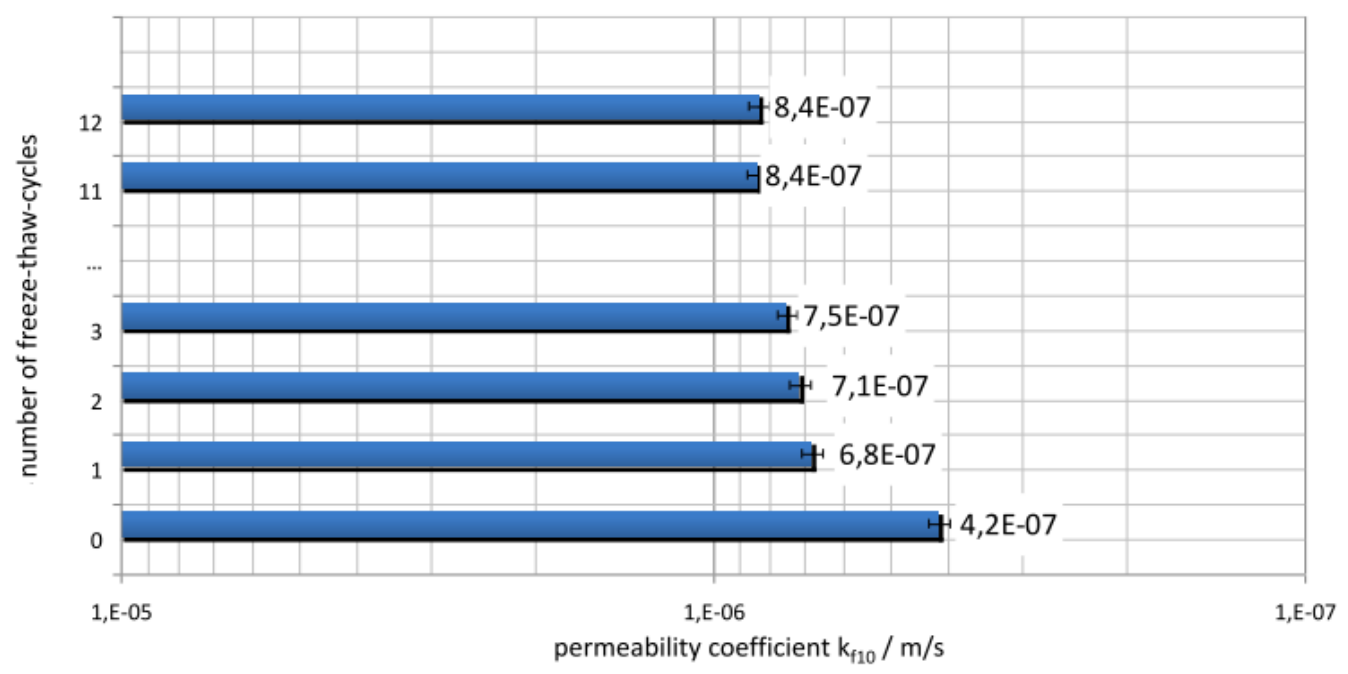

Figure 3 Vertical hydraulic conductivity of system sample B before and after freeze-thaw cycle stress. The first cycle caused the most significant increase in permeability.

The comparison with the reference measurements of the preliminary tests with grouting material samples showed that the $\mathrm{k}_{\mathrm{f} 10}$-values of the system samples were about 2 orders of magnitude above the values of the pure material samples (see Figure 4). The first freezing cycle had the second largest influence, the remaining freezing cycles were the third largest influence. For all materials, the first 11 freeze cycles led to a degradation of approximately 0.5 to 1 order of magnitude. In contrast, the system samples showed individual regeneration behavior, so that the sum of the effects at the end of the experiment came to 2.5 to 3 orders of magnitude. Figure 4 shows this relation for four grouting materials. The temporal relations must be considered as follows: the age of the material samples corresponds to about 2 months. The measured values of the system samples, expressed as mean values, correspond to an age of 3 to 5 months for the undisturbed system samples and about 4 to 9 months after 11 freeze-thaw cycles. Higher sample age generally leads to lower permeability.

After the measurements, the system samples were removed from the pressure vessel and sliced. Significant visible changes in the structure or detachment of the HEPs from the grouting material could not be verified. Air holes in the backfill material and accumulations below spacers were observed but did not result in a continuous porous matrix.

The sanded layer on the inside of the plastic tube, which was supposed to prevent water flow between the grouting material and plastic tube, was fully intact. In system sample C and D a dye tracer was used and was mainly detectable in the very direct vicinity of the layer around the U-bend it was deposited in. For the area in which dye tracks could be found, coloration occurred mainly at the transition between the grouting material and the HEPs. 


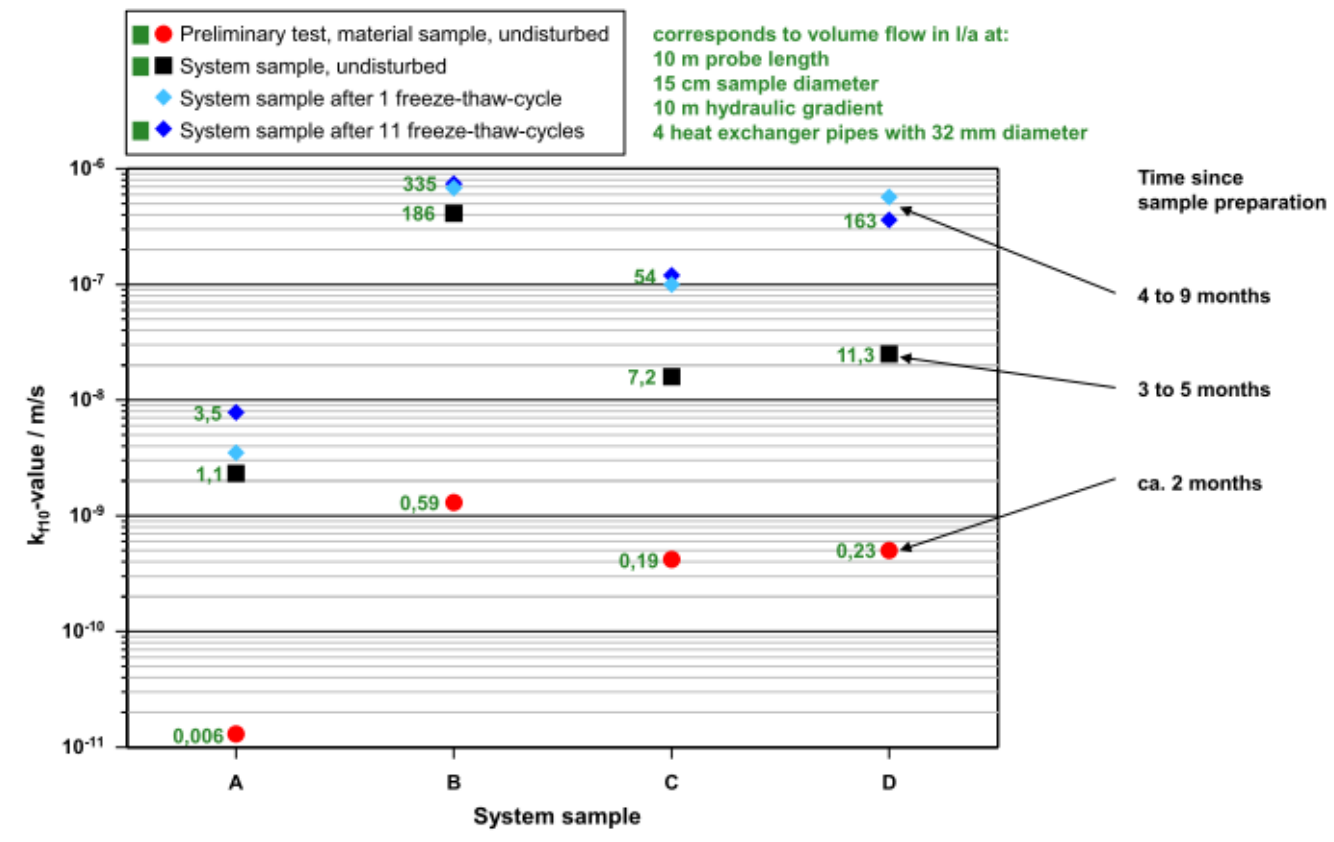

Figure 4 Comparison between the results from four system samples in the large-scale test rig and the material samples of the preliminary tests. The mean values of the system samples show markedly increased permeability, which is further increased by freeze-thaw cycle stress. The first freeze-thaw cycle generally caused an increase, the value stabilizes during the following cycles and was partially compensated, in particular for sample $\mathrm{D}$, by regeneration effects. The green figures represent the water flow in a hypothetical $10 \mathrm{~m}$ sample with $15 \mathrm{~cm}$ diameter and hydraulic gradient of $10 \mathrm{~m}$. This is a realistic example for a geological barrier layer at an in-situ BHE.

\section{DOWNSCALED TEST RIG}

The aim of this rig is to develop a test method which combines the advantages of the known approaches. For example, the geometry and installation conditions of a BHE are to be reproduced in a realistic manner. The borehole diameter and HEPs, including internal installations such as a grouting hose and spacers, need to correspond to the condition in an in-situ BHE. The operational conditions, especially the depth of the borehole, have to be represented by a corresponding pressurization of the entire test rig. Also, the backfilling procedure for producing a sample is the same as for a real BHE. The sample length, however, is chosen to allow for an acceptable duration of the measurements and easier handling of the samples.

\section{Requirements definition}

The following is a list of the essential requirements which resulted from considering the known methods.

- A membrane (e.g. made of latex) should be used analogously to the triaxial cells according to DIN 18130-1 (DIN 18130-1, 1998) to avoid water flow around the test specimens.

- The size of the test rig should allow for the installation of system samples with a length of up to $1000 \mathrm{~mm}$.

- The installation of system samples with a diameter of $150 \mathrm{~mm}$ and four HEPs with a diameter of $32 \mathrm{~mm}$ each or samples with a diameter of $100 \mathrm{~mm}$ and one HEP with a diameter of $40 \mathrm{~mm}$ should both be possible.

- The test rig should withstand saturation pressures of up to 9 bar. 
- For visual evaluation of the freeze-thaw cycle and the condition of the latex membrane, the pressure vessel should be transparent or partly transparent

- Freeze-thaw cycle stress should be achievable without the test specimen being depressurized or removed from the test rig.

- The freeze-thaw cycle stress of the system sample should take place from the center to the outside.

- The system samples should be produced in a realistic manner using the tremie method

- Optionally, the system sample can be radially clamped to prevent expansion during the freeze-thaw cycle.

Based on these requirements, the following concept was developed for measuring the vertical hydraulic conductivity of BHES samples.

\section{Concept for the downscaled test rig}

The new test rig is based on the model of a triaxial cell according to DIN 18130-1 (DIN 18130-1, 1998). All the above listed requirements are met. Especially the rig's ability to hold various types of samples should be emphasized. The length of the system samples can be up to one meter. With a simple modification of the test rig, samples of 150 $\mathrm{mm}$ or $100 \mathrm{~mm}$ diameter can be used. Optionally, other sample sockets can be designed to fit various sample diameters and HEP configurations.

The partly transparent pressure vessel shown in Figure 5 allows for observation of the freeze-thaw cycle stress as well as the entire testing procedure. This is useful, for example, to monitor the state of the latex membrane.

Compared to the large-scale test rig, the downscaled one has the important advantage of shorter sample sizes, which facilitates test execution. For example, the test specimens are easier to handle and the test duration is significantly shortened.
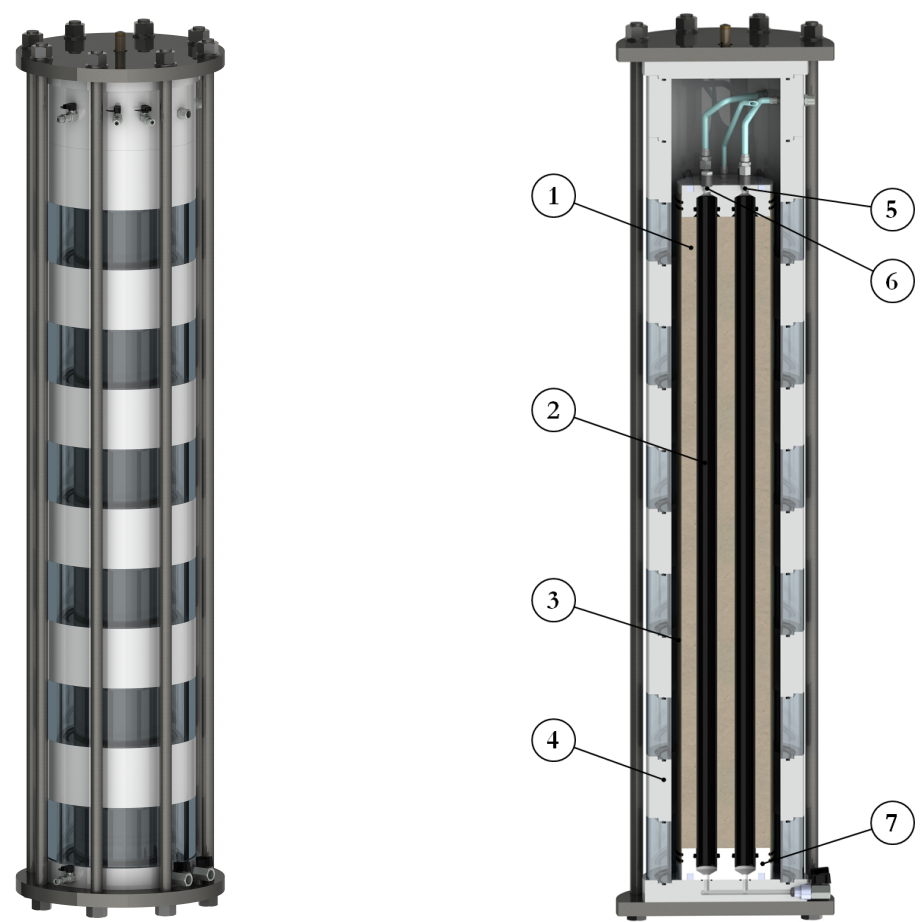

Figure 5 Concept for the downscaled test rig in isometric view (left) and sectional view (right). 1) grouting material, 2) heat exchanger pipes, 3) latex membrane, 4) pressure vessel wall, 5) fluid circulation inlet, 6) fluid circuit outlet and 7) sample socket. The vessel wall is made of alternatingly transparent and opaque rings due to cost and production process. 
The possibility to vary sample length, sample cross section, number and diameter of the HEPs allows for free dimensioning of the sample. The experimental concept allows for experiments to be carried out to find the optimal experimental setup for a suitable material testing method for BHES. For example, experimental investigation on whether a simplified sample geometry is comparable to that of an in-situ installed double-U-pipe. Also, an experimental determination which minimal sample length is possible without reducing the significance of the $\mathrm{k}_{\mathrm{f}}$-value measurements.

By choosing different saturation pressures, optimized saturation can be achieved and different depth positions of the BHE can be simulated. In addition, the separation of the inlet and the outlet of the sample fluid circuit can be used to realize a depth dependent, horizontal temperature gradient by means of a corresponding external interconnection. For example, it would be feasible for the inlet of the system sample to exhibit a temperature difference of $5 \mathrm{~K}$ to the outlet.

\section{CONCLUSION}

The previous examination of industrially produced grouting materials has proven that the vertical hydraulic system conductivity increases after freeze-thaw cycle stress at $-6^{\circ} \mathrm{C}$. However, even after several cycles the increase of the $\mathrm{k}_{\mathrm{f}}$-values is in the range of one order of magnitude, which is acceptable. It must yet be considered that the permeability of the grouting material always needs to be adjusted to the individual permeability of the geological surroundings of the borehole. The difference of the $\mathrm{k}_{\mathrm{f}}$-values of three orders of magnitude between the system samples and material samples shows an obvious restriction and applies only to the type of system tested here using PE100-pipes. Therefore, each material must be evaluated individually since general derivations cannot be applied to individual materials.

Another challenge is to cover a wide measuring range from $10^{-5} \mathrm{~m} / \mathrm{s}$ to $10^{-11} \mathrm{~m} / \mathrm{s}$ for the $\mathrm{k}_{\mathrm{f} 10^{-}}$-values. For this purpose, high measurement accuracy and reproducibility of the results were achieved by optimizing the temperature stability of the test rig. The experimental setup is very complex and time-consuming. For example, the evaluation (incl. freeze-thaw cycles) of a single system sample takes at least 2 months.

Moreover, it has been found that an extremely careful execution of the experimental procedure and precisely controlled boundary conditions are crucial to achieve the necessary high measuring accuracy.

Consequently, the Bavarian Center for Applied Energy Research is building a smaller scaled test rig in a running project, which brings together the advantages of the previously known methods in one test rig. Due to the possibility of variable sample dimensions, the method is not restricted by predetermined scaling conditions of the test rig.

At the time of submission of these proceedings, the experimental setup is in the detail-planning phase and some parts have already been constructed. By the time of the presentation at the IGSHPA Research Track, the construction of the test rig will have been finalised and the first downscaled system sample will have been installed.

\section{ACKNOWLEDGMENTS}

We would like to thank the German Federal Ministry for Economic Affairs and Energy for granting the two projects (Grant Numbers: 0327453A and 03ET1386A).

\section{REFERENCES}

Anbergen, H., Frank, J., Müller, L. and Sass, I. 2014a. Freeze-Thaw-Cycles on Borehole Heat Exchanger Grouts: Impact on the Hydraulic Properties, Geotechnical Testing Journal, Vol 37, Num. 4, 2014.

Anbergen, H., Frank, J., Reuß, M., Kuckelkorn, J. M., Müller, L. and Sass, I. 2015. Hydraulische Integrität des Systems Erdwärmesonde. bbr - Fachmagazin für Brunnen- und Leitungsbau, 02-2015: 34-41. 
Anbergen, H., Frank, J. and Sass, I. 2012. Quality assurance of grouting for Borehole Heat Exchangers. The 12th International Conference on Energy Storage, Innostock 2012. Lleida, Spain.

Anbergen, H., and Sass, I. 2013. Freeze-thaw-behaviour: Observations in Grouted BHES. Thirty-Eighth Workshop on Geothermal Reservoir Engineering, Stanford University. Stanford, California.

Anbergen, H., Reuß, M., Kuckelkorn, J. M., Frank, J., Müller, L. and Sass, I. 2014b. Hydraulische Integrität des Systems Erdwärmesonde. Der Geothermiekongress 2014. Essen, Germany.

DIN 18130-1. 1998. Baugrund - Untersuchung von Bodenproben; Bestimmung des W asserdurchlässigkeitsbeiwertes - Teil 1: Laborversuche. Berlin: Deutsches Institut für Normung e. V. [PP], Beuth Verlag.

Hölting, B. and Coldewey, G. 2008. Hydrogeologie: Einführung in die Allgemeine und Angewandte Hydrogeologie. Heidelberg, Germany: Spektrum Akademischer Verlag.

Kirschbaum, A., Kuckelkorn, J. M. and Hagel, K. 2017. Konzept für einen Versuchsaufbau zur Messung der bydraulischen Systemdichtheit von Erdwärmesonden. Der Geothermiekongress 2017. Munich, Germany.

Kuckelkorn, J. M. 2013. Systemdichtheit von Verfüllbaustoffen. 12. Internationales Anwenderforum Oberflächennahe Geothermie, OTTI. Regensburg, Germany.

Kuckelkorn, J. M., Biank M. and Reuß, M. 2010. Großversuchsstand zur Bestimmung der bydraulischen Durchlässigkeit von Erdwärmesonden-Systemen. 10. Internationales Anwenderforum Oberflächennahe Geothermie, OTTI. Regensburg, Germany.

Kuckelkorn, J. M. and Reuß, M. 2010. Untersuchung der bydraulischen Durchlässigkeit von Erdwärmesonden-Systemen. Der Geothermiekongress 2010. Karlsruhe, Germany.

Kuckelkorn, J. M. and Reuß, M. 2012. Methodik und Ergebnisse zur bydraulischen Durchlässigkeit von Verfüllbaustoffen bei Erdwärmesonden - Bestimmung des kef-Wertes und Alterung von Erdwärmesonden-Systemen in einem Großversuchsstand. 3. VDIFachkonferenz Wärmepumpen, VDI Wissensforum GmbH. Düsseldorf, Germany.

Reuß, M., Koenigsdorff, R., Zorn, R., Kuckelkorn, J., Steger, H., Pröll, M. and Feuerstein, P. 2012. Final Report, Qualitätssicherung bei Erdwärmesonden und Erdreichkollek.toren. Bundesministerium für Wirtschaft und Technologie (Grant Number 0327453A).

VDI 4640 - Blatt 2 2015. Thermische Nutzung des Untergrundes - Erdgekoppelte Wärmepumpenanlagen (Entwurf). Berlin: Verein Deutscher Ingenieure (PP), Beuth Verlag. 